\title{
MASSIVE BLEEDING IN SMALL BOWEL DIVERTICULOSIS
}

\author{
Sergey Glinkov ${ }^{1}$ Evgeni Kiryazov ${ }^{1}$, Boris Kornovski ${ }^{1}$, Pavel Pavlov², Todor Alexiev ${ }^{2}$ \\ ${ }^{1}$ Department of Surgery, St. Anna University Hospital of Varna \\ ${ }^{2}$ Department of General and Clinical Pathology, Forensic Medicine and Deontology, \\ Medical University of Varna
}

\begin{abstract}
INTRODUCTION: Diagnosis of small bowel diverticulosis complications is difficult in the emergency setting and often delays surgical management. The aim of this study was to report our experience with three patients presenting with surgical complication of small bowel diverticulosis with massive bleeding.

PATIENTS AND METHODS: From January 2015 to February 2017, three patients, two males and one female, presenting with bleeding as a complication of small bowel diverticulosis were included in this study. Their mean age was 70 years.

RESULTS: The mean duration between the complication onset and its management was 8.3 days. Gastroendoscopy and colonoscopy were used to eliminate stomach and colon bleeding. All the patients were operated on. Segmental small bowel resection was performed with primary anastomosis without any complications.

CONCLUSION: Small bowel diverticulosis is a rare pathology. In cases of gastrointestinal hemorrhage, diagnosis is performed by eliminating the bleeding from gastroduodenal and colonic segment of the gastrointestinal tract. The diagnosis has been established through exploratory laparotomy only. Scr Sci Med 2017; 49(3): 40-44
\end{abstract}

Keywords: jejunal diverticulosis, bleeding

\section{INTRODUCTION}

Intestinal tract diverticulosis is a rare disease. According to autopsy protocols, its incidence rate ranges from 0.1 to $2.7 \%$ (1). The disease occurs asymptomatically and clinical symptoms occur in case of complications such as perforation, intestinal obstruction and intestinal hemorrhage manifested by melena and hematemesis.

Address for correspondence:

Assoc. Prof. Sergey Glinkov, MD, PhD

Department of Surgery

St. Anna University Hospital of Varna

100 Tsar Osvoboditel Blvd

Varna 9002, Bulgaria

e-mail:sglinkov@yahoo.com

Received: August 22, 2017

Accepted: September 15, 2017
While in perforation and intestinal obstruction urgent laparatomy rapidly establishes the diagnosis, in cases of bleeding the diagnosis is difficult and untimely. Subsequently, delayed diagnosis results in delayed surgical treatment.

The purpose of this article is to share the diagnostic problems and surgical treatment in our patients who have been hospitalized in the emergency division when diagnosed with melena and hematemesis.

\section{PATIENTS AND METHODS}

During the period from 2015 to 2017, 156 patients were admitted to the Division of Emergency Surgery of St. Marina University Hospital of Varna with a diagnosis of melaena and hematemesis verified by standard gastroduodenoscopy and colonoscopy. In three of these patients (in 1.92\% of the cases), the repeated endoscopy failed to establish the source of bleeding. The bleeding reiterated many times and 
Glinkov, Kiryazov, Kornovski et al.

led to a breakdown in hemodynamic and hematological indicators, thus requiring a second gastroscopy with a negative result. Only the small bowel tract was left unexamined. Profuse bleeding required surgical treatment with the assumption that the source of bleeding was in the small intestine.

\section{RESULTS} on Table 1.
Preoperative patients' characteristics are shown

Table 1. Preoperative patients' characteristics
In these three patients, jejunal diverticulosis with a length of $60-70 \mathrm{~cm}$ was intraoperatively found out at a distance of $15-20 \mathrm{~cm}$ from the duodeno-jejunal transition (Fig. 1). A pronounced inflammatory reaction of the diverticula was observed macroscopically in one patient. It was localized at the highest point and adhered to the transverse colon. In the remaining two patients, the diverticulosis site was loose in the abdominal cavity.

From the beginning of the polyposis segment,

\begin{tabular}{|c|c|c|c|c|c|c|c|c|}
\hline $\begin{array}{l}\text { Patient } \\
\text { No }\end{array}$ & $\begin{array}{c}\text { Age } \\
\text { (years) }\end{array}$ & $\begin{array}{l}\text { Clinical } \\
\text { features }\end{array}$ & $\mathrm{Hb}$ & Er & Ht & Endoscopy & $\begin{array}{c}\text { Blood } \\
\text { transfusion/ } \\
\text { days }\end{array}$ & $\begin{array}{c}\text { Preoperative } \\
\text { stay/days }\end{array}$ \\
\hline 1. & 77 & melena & 88 & 2.6 & 0.28 & $\begin{array}{l}\text { GDS - neg. } \\
\text { CS - neg. }\end{array}$ & $276 \mathrm{~mL}$ & 9 \\
\hline 2. & 69 & $\begin{array}{c}\text { melena, } \\
\text { hematemesis }\end{array}$ & 78 & 2.3 & 0.29 & $\begin{array}{l}\text { GDS - neg. } \\
\text { CS - neg. }\end{array}$ & $1209 \mathrm{~mL}$ & 2 \\
\hline 3. & 64 & $\begin{array}{l}\text { melena, } \\
\text { collapse }\end{array}$ & 50 & 1.3 & 0.14 & $\begin{array}{c}\text { GDS - neg. } \\
\text { CS - diverticulosis, } \\
\text { no bleeding }\end{array}$ & $1798 \mathrm{~mL}$ & 9 \\
\hline
\end{tabular}

legend: GDS - Gastroduodenoscopy, CS - colonoscopy

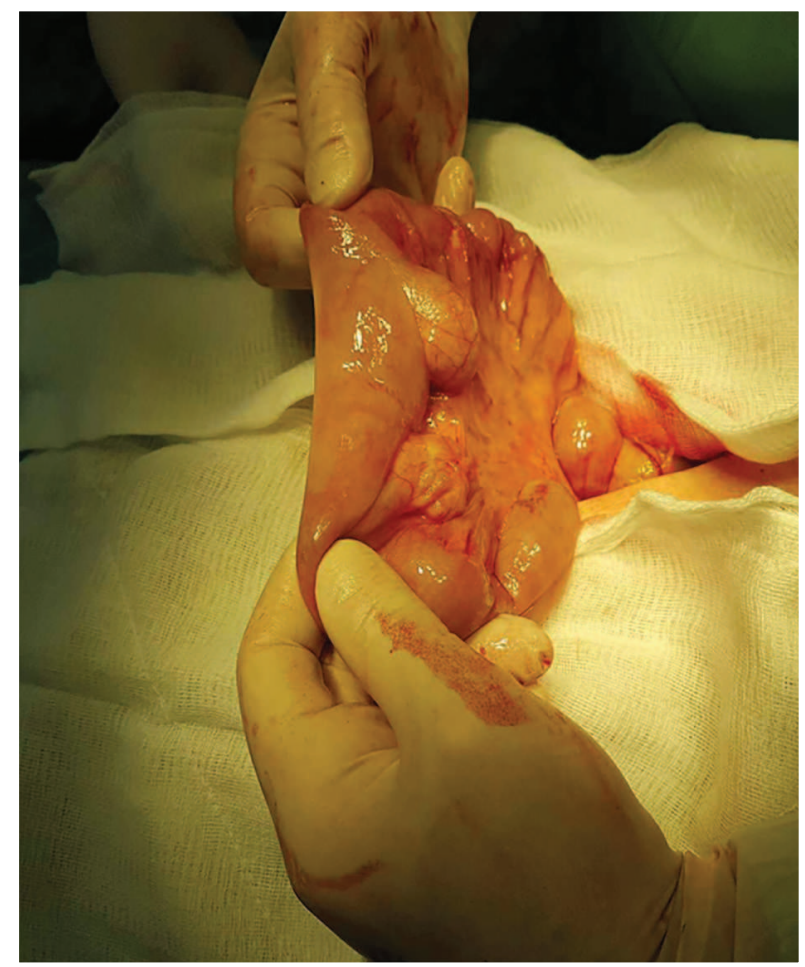

Fig. 1. Macroscopic appearance of the jejunal diverticulosis the intestinal lumen was filled with blood that did not require intraoperative endoscopy. Resection of the polyposis segment with subsequent termino-terminal anastomosis was performed (Table 2).

There were no complications during the postoperative period. The patients were discharged with stable hematological and hemodynamic parameters (Table 2). Pathohistological studies showed a pronounced inflammatory reaction in the first patient (Table 2). In all three patients, there was no muscular tunic. Protraction of mucosa and submucosa through the muscle layer was present (Fig. 2).

Venous and arterial vessels were blood-filled and presented with a thinned wall (Fig. 3). Lymphocyte and leukocyte infiltration was observed around the vessels (Fig. 4).

Micrograph of diverticulosis demonstrated many blood vessels located between the mucosa and muscular tunic presenting with tortuous contours. There was increased arterial wall thickening. The inflammatory infiltration in this area had partially destroyed the vascular wall. Surrounding connect- 
Table 2. Surgical and pathohistological features

\begin{tabular}{|c|c|c|c|}
\hline $\begin{array}{l}\text { Patient } \\
\text { No }\end{array}$ & Operative finding & Surgery & Pathohistology \\
\hline 1 & $\begin{array}{l}\text { Jejunal diverticulosis at } 30 \\
\mathrm{~cm} \text { from the duodeno-jejunal } \\
\text { transition. } \\
\text { Expressed inflammatory reaction } \\
\text { with diverticulum adhered to the } \\
\text { transverse colon }\end{array}$ & $\begin{array}{l}\text { Resection of the diverticular } \\
\text { segment }\end{array}$ & $\begin{array}{l}\text { Stagnation in the bloodstream } \\
\text { of the wall. Thinned vessel } \\
\text { wall along with leukocyte and } \\
\text { lymphocyte infiltration }\end{array}$ \\
\hline 2 & $\begin{array}{l}\text { Jejunal diverticulosis at } 20 \\
\mathrm{~cm} \text { from the duodeno-jejunal } \\
\text { transition. } \\
\text { No inflammatory reaction }\end{array}$ & $\begin{array}{l}\text { Resection of the diverticular } \\
\text { segment }\end{array}$ & $\begin{array}{l}\text { Stagnation in the bloodstream } \\
\text { of the wall. Thinned vessel } \\
\text { wall along with leukocyte and } \\
\text { lymphocyte infiltration }\end{array}$ \\
\hline 3 & $\begin{array}{l}\text { Jejunal diverticulosis at } 20 \\
\mathrm{~cm} \text { from the duodeno-jejunal } \\
\text { transition. } \\
\text { No inflammatory reaction }\end{array}$ & $\begin{array}{l}\text { Resection of the diverticular } \\
\text { segment }\end{array}$ & $\begin{array}{l}\text { Stagnation in the bloodstream } \\
\text { of the wall. Thinned vessel } \\
\text { wall along with leukocyte and } \\
\text { lymphocyte infiltration }\end{array}$ \\
\hline
\end{tabular}

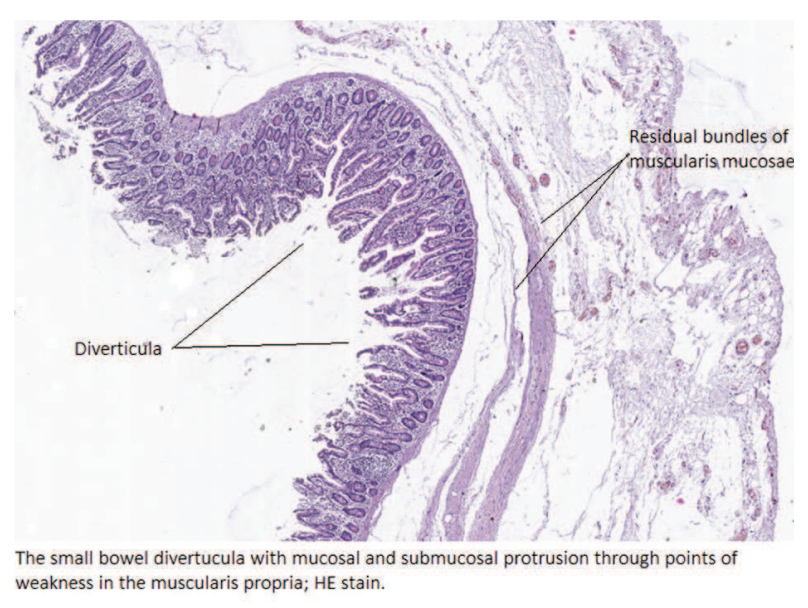

Fig. 2. Protraction of mucosa and submucosa through the muscle layer

ing tissues demonstrated evidence of vascular congestion and infiltration by lymphocytes, eosinophils and neutrophils.

\section{DISCUSSION}

Small bowel polyposis was described for the first time by Sumaring in 1794, and a more detailed description was made by Sir Asteli in 1807. It is classified as false diverticulosis because it lacks a muscle layer. In this case, the mucosa and the submucosal layer pass through the muscle layer in the form of a sac (2). Usually, the polyposis is multiple and localized in the small intestine. The diverticula are located in the mesenterial part of the intestinal wall, where mesenteric vessels enter, too (3).

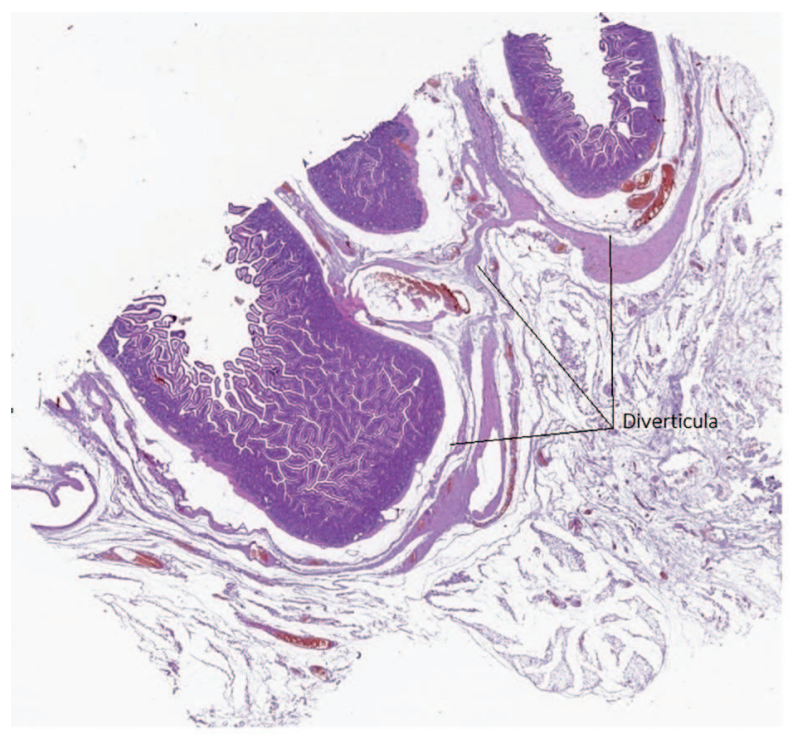

Photomicrograph (original magnification, $\times 400$; HE stain) represents the small bowel affected by multiple diverticula. Note typical herniation of the intestinal mucosa and submucosa through residual bundles of muscularis mucosae. All the diverticula show chronic diverticulosis.

Fig. 3. Photomicrograph of blood-filled venous and arterial vessels

Clinically, diverticulosis occurs asymptomatically and its clinical manifestation occurs in case of complications such as perforation (4), intestinal obstruction (5), and bleeding (6). The bleeding may occur as occult bleeding or in the form of massive melena and hematemesis (7) leading to a breakdown of hematological indicators. According to Pras, the bleeding rate ranges between $6 \%$ and $20 \%$ (cited after 8). The bleeding in the small intestine can be ob- 


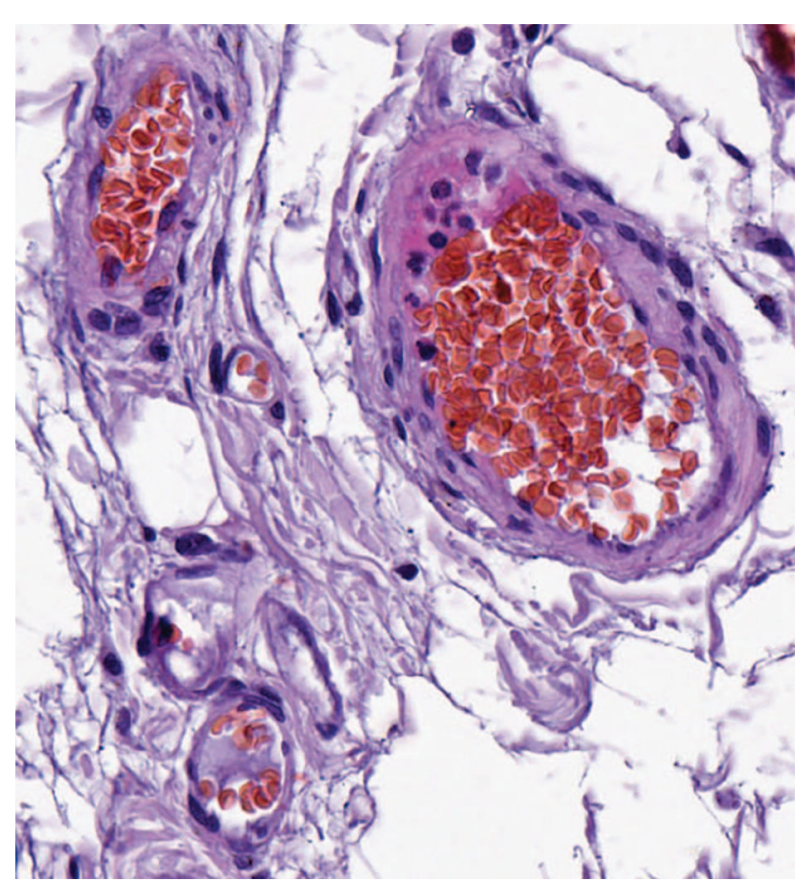

Fig. 4. Perivascular lymphocyte and leukocyte infiltration

served in angiodisplasia (9) or in primary and metastatic tumours located in other organs (1).

Endoscopy for gastrointestinal tract imaging is a basic method for recognizing the problems in the intestinal tract. However, it is extremely difficult in the small intestine and requires special endoscopic equipment $(7,10)$ as well as a specialized endoscopic team. These preconditions are available in the most technologically advanced hospitals in our country only. The use of such equipment, usually in an emergency setting, is difficult to apply due to time deficiency. This applies to angioscopic and scintigraphic methods (10). In these cases, clinical assessment by means of urgent laparatomy remains at surgeon's disposal only. Intraoperative endoscopy is applicable here despite the risk of abdominal cavity contamination (3). In this case, when blood is present in the diverticulous segment, as in our patients, segmental resection with subsequent primary anastomosis can be performed. A segmental small bowel resection is successfully carried out in six patients presenting with a complication of small-bowel diverticulosis (11).

Morphologically, small bowel diverticulum is a sac-shaped mucosal and submucosal protrusion through the muscle layer. Mucosal ulcerations (10) can be observed, too. The changes are mainly in the vascular structure and expressed as blood-filling, folding and possible rupture of arterial vessels (8). The arterial wall is thinner and there is an increased infiltration by lymphocytes and leukocytes around the vessels.

We find out ulceration in one of our patients only. According to Kamura, if there is no ulceration, a blood vessel rupture can occur (cited after 8). The structural changes in the wall of the diverticula and the increased intraluminal pressure are the probable cause of the rupture (8).

\section{CONCLUSION}

In patients admitted with massive melaena and hematemesis, if the bleeding source is not established through gastroduodenoscopy and colonoscopy, it should be assumed that it is located in the small intestinal tract. When fine-grain polyposis is detected, surgeon's behaviour should consist in resection of the polyposis site with primary anastomosis.

\section{REFERENCES}

1. Arabadzhieva E, Benev S, Takov P, Dimitrova V. Surgical treatment of complicated forms of gastrointestinal tract diverticulosis. Bulg Med J. 2012;(1):58-63 (in Bulgarian)

2. Hartmann D, Schmidt H, Bolz G, Schilling D, Kinzel F, Eickhoff A, et al. A prospective twocenter study comparing wireless capsule endoscopy with intraoperative enteroscopy in patients with obscure GI bleeding. Gastrointest Endosc. 2005;61(7):826-32. doi: .org/10.1016/ S0016-5107(05)00372-X

3. Hsu PS, Chen JL, Yu JC, Hsieh CB, Shih ML. Accurate diagnosis and successful treatment for massive obscure small intestinal bleeding by means of intra-operative enteroscopy: a case report. Eur J Gastroenterol Hepatol. 2008;20(2):139-41. doi: 10.1097/ MEG.0b013e32825a6ac6.

4. Kornprat P, Langner C, Mischinger HJ. Enterolithiasis in jejunal diverticulosis, a rare cause of obstruction of the small intestine: a case report. Wien Klin Wochenschr. 2005;117(7-8):297-9.

5. Liu CK, Chang KM. Massive bleeding from a ruptured artery in jejunal diverticulosis without preexisting mucosal inflammation or ulceration. Clin J Gastroenterol. 2009;2(2):85-8. doi: 10.1007/ s12328-008-0048-6.

6. Songné $\mathrm{B}$, Costaglioli $\mathrm{B}$, Michot $\mathrm{F}$, Ténière $\mathrm{P}$, Scotté M. Management of surgical compli- 
Massive Bleeding in Small Bowel Diverticulosis

cations of small-bowel diverticulosis. Gas-

troenterol Clin Biol. 2005;29(4):415-8. doi:

GCB-04-2005-29-4-0399-8320-101019-200513281.

7. Monchal T, Hornez E, Bourgouin S, Sbardella F, Baudoin Y, Butin C, et al. Enterolith ileus due to jejunal diverticulosis. Am J Surg. 2010;199(4):e45-7. doi: 10.1016/j.amjsurg.2009.05.042.

8. Tiwary SK, Hakim MZ, Kumar P, Khanna AK. Jejunal angiodysplasia causing recurrent gastrointestinal bleeding presenting as severe anaemia and melena. BMJ Case Rep. 2015 Nov 13;2015. doi: 10.1136/bcr-2015-212798.

9. Jansen JM, Oldenburg B, van Milligen de Wit AW. Small intestinal metastasis from nonsmall-cell carcinoma of the lung: a rare cause of GI bleeding of obscure origin. Gastrointest Endosc. 2004;59(3):447-9. doi: org/10.1016/ S0016-5107(03)02536-7

10. Vilallonga R, Sanchez Garcia JL, Armengol M, Iordache N. Jejunal diverticula causing massive intestinal bleeding. Chirurgia (Bucur). 2012;107(5):652-4.

11. Pennazio M. Introduction to small-bowel bleeding. Tech Gastrointest Endosc 2012;14(2):94-9. 